\title{
Article \\ A Novel Prognostic Biomarker Panel for Early-Stage Colon Carcinoma
}

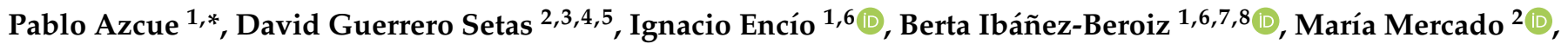 \\ Ruth Vera ${ }^{5,6}$ and María Luisa Gómez-Dorronsoro ${ }^{2,6, *}$
}

check for updates

Citation: Azcue, P.; Guerrero Setas, D.; Encío, I.; Ibáñez-Beroiz, B.;

Mercado, M.; Vera, R.;

Gómez-Dorronsoro, M.L. A Novel

Prognostic Biomarker Panel for

Early-Stage Colon Carcinoma.

Cancers 2021, 13, 5909.

https://doi.org/10.3390/

cancers13235909

Academic Editors: Frank A. Sinicrope and Jesús García-Foncillas

Received: 28 September 2021

Accepted: 22 November 2021

Published: 24 November 2021

Publisher's Note: MDPI stays neutral with regard to jurisdictional claims in published maps and institutional affiliations.

Copyright: (c) 2021 by the authors. Licensee MDPI, Basel, Switzerland. This article is an open access article distributed under the terms and conditions of the Creative Commons Attribution (CC BY) license (https:// creativecommons.org/licenses/by/ $4.0 /)$.
1 Department of Health Science, Public University of Navarra, 31008 Pamplona, Spain; ignacio.encio@unavarra.es (I.E.); berta.ibanez.beroiz@navarra.es (B.I.-B.)

2 Department of Pathology, University Hospital of Navarra, 31008 Pamplona, Spain; dguerres@navarra.es (D.G.S.); mr.mercado.gutierrez@navarra.es (M.M.)

3 Campus Arrosadia, Public University of Navarra, 31006 Pamplona, Spain

4 Molecular Pathology of Cancer Group-Navarrabiomed, 31008 Pamplona, Spain

5 Department of Medical Oncology, University Hospital of Navarra, 31008 Pamplona, Spain; ruth.vera.garcia@navarra.es

6 Institute for Health Research Navarra (IdISNA), 31008 Pamplona, Spain

7 Unit of Methodology-Navarrabiomed-University Hospital of Navarra, 31008 Pamplona, Spain

8 Research Network on Health Services Research and Chronic Diseases (REDISSEC), 31008 Pamplona, Spain

* Correspondence: azcue.136628@e.unavarra.es (P.A.); ml.gomez.dorronsoro@navarra.es (M.L.G.-D.)

Simple Summary: Decision about treatment choice in early-stage colon cancer may be difficult for clinicians because of a lack of published data. Colon cancer is a very heterogeneous disease, but some previous efforts have helped us elucidate potential biomarkers for characterizing patients. Our goal is to create a panel of biomarkers capable of differentiating patients with a low, medium, and high risk of death or relapse. Our results suggest that, by combining PD-L1, GLUT-1, and mismatch repair proteins in a biomarker panel, patients could be significantly and evenly divided into one of these three groups. The resulting biomarker panel has the potential clinical value that, by being able to classify a patient with early colon cancer as being at high risk of death or tumor evolution, they could benefit from a more aggressive early treatment, while this approach might not be needed for low-risk patients.

Abstract: Molecular characterization of colorectal cancer has helped us understand better the biology of the disease. However, previous efforts have yet to provide significant clinical value in order to be integrated into clinical practice for patients with early-stage colon cancer (CC). The purpose of this study was to assess PD-L1, GLUT-1, e-cadherin, MUC2, CDX2, and microsatellite instability (dMMR) and to propose a risk-panel with prognostic capabilities. Biomarkers were immunohistochemically assessed through tissue microarrays in a cohort of 144 patients with stage II/III colon cancer. A biomarker panel consisting of PD-L1, GLUT-1, dMMR, and potentially CDX2 was constructed that divided patients into low, medium, and high risk of overall survival or disease-free survival (DFS) in equally sized groups. Compared with low-risk patients, medium-risk patients have almost twice the risk of death $(\mathrm{HR}=2.10(0.99-4.46), p=0.054)$, while high-risk patients have almost four times the risk $(\mathrm{HR}=3.79(1.77-8.11), p=0.001)$. The multivariate goodness of fit was 0.756 and was correlated with Kaplan-Meier curves $(p=0.002)$. Consistent results were found for DFS. This study provides a critical basis for the future development of an immunohistochemical assessment capable of discerning early-stage CC patients as a function of their prognosis. This tool may aid with treatment personalization in daily clinical practice and improve survival outcomes.

Keywords: PD-L1; GLUT-1; MUC2; e-cadherin; CDX2; CMS; colon cancer; prognostic biomarker 


\section{Introduction}

Colorectal cancer (CRC) is the second most common cause of cancer deaths worldwide [1]. The overall 5-year patient survival rate has recently risen to almost two-thirds [2], partly due to curative oncological colon or rectal surgery, neoadjuvant treatments, and better long-term functional outcomes once the metastatic state has been reached [3].

CRC is a highly heterogeneous disease; earlier efforts have helped us understand the molecular events that play a crucial role in prognosis and treatment decisions. This is the case for microsatellite instability (MSI) or mismatch repair (MMR) protein deficiency for adjuvant therapy and KRAS (exon2), BRAF (V600E), and PIK3CA for anti-epidermal growth factor (anti-EGFR) therapy in the metastatic setting [4-8]. Additionally, technical advances have enabled further characterization through molecular profiling, including candidate cancer genes [9], Jass classification [10], Ogino classification [11], colorectal cancer intrinsic subtypes [12], and most recently, the consensus molecular subtype (CMS) [13].

It has become clearer that molecular events and gene alterations play a crucial role in the tumoral evolution. However, the previously mentioned characterization efforts have not been able to provide results of sufficient clinical significance to merit inclusion in international guidance and to change daily clinical practice. Nevertheless, these efforts have helped elucidate the main molecular signaling pathway aberrations and interactions, gene expression profiles, and pathological characteristics contributing to the complex tumoral evolution process [14,15].

The CMS classification has come closest to providing predictive capabilities with therapeutic implications through transcriptomics [16]. However, it continues not to be part of clinical practice, probably due to the highly specialized resources needed to carry it out, the failure to ascribe a defined molecular profile to $13 \%$ of the population, and the lack of a clear prognostic or predictive value (especially for the CMS2 and CMS3 subtypes). Nonetheless, the CMS classification has helped us better understand the molecular targets that can prove useful for biomarker selection. In a nutshell, the CMS2 or canonical subtype is characterized by chromosomal instability, with marked WNT and MYC signaling activation pathways with APC and TP53 mutations. The CMS3 or metabolic subtype is characterized by metabolic dysregulation with KRAS and APC mutations. CMS2 and CMS3 subtypes share characteristics with CMS1 (MSI-immune) and CMS4 (mesenchymal) subtypes, presenting a mixed prognosis in an early-stage and metastatic setting [17-20]. Further efforts are needed to find biomarkers capable of characterizing these patients, which are ideally easier to assess and implement in clinical practice.

Programmed cell death protein 1 (PD-1) and its ligand (PD-L1), glucose transporter 1 (GLUT-1), e-cadherin, mucin 2 (MUC2), and caudal-related homeobox transcription factor 2 (CDX2) are proteins that share plausible mechanisms with the CMS subtypes and their molecular profiles. They are also feasible to assess through immunohistochemistry (IHC), which might satisfy the need to clarify the prognosis of early-stage colon cancer patients.

Programmed cell death protein 1 (PD-1) or CD279 is an inhibitory receptor that is expressed by $\mathrm{T}$ cells during activation. PD-L1 expression in the tumor microenvironment interacts with PD-1 in tumor-infiltrating lymphocytes, attenuating the tumor-triggered T-cell response [21]. The activation of the $\mathrm{WNT} / \beta$-catenin pathway by this receptor is among the signaling pathways that have been elucidated in CRC. It has been linked to progression [22] and the epithelial-mesenchymal transition (EMT) [23]. Additionally, PDL1 receptor inhibition has been associated with the immune-related lymphocyte response that produces TGF $\beta$ [24]. Consequently, potential synergistic effects have recently been proposed between immune checkpoint inhibitors and TGF $\beta$ receptor inhibitors, with therapeutic implications in CRC $[25,26]$.

Glucose transporter 1 (GLUT-1) is a transmembrane protein glucose transporter that is crucial in the glucose metabolism. Overexpression of GLUT-1 has been reported in different types of solid tumors including CRC $[27,28]$, and it has been related to cancer cell proliferation and the provision of stress protection to the tumor [29]. GLUT-1 has been 
proposed as a potential marker for malignant transformation, with a probable direct link between the degree of overexpression and aggressiveness [30,31].

As a member of the calcium-dependent cell adhesion molecules (CAMs), e-cadherin is believed to be one of the most important adhesion molecules of epithelial tissues [32]. Downregulation of e-cadherin has been associated with tumor progression, loss of differentiation, and metastasis, probably due to its involvement in the EMT [33-35]. The value of e-cadherin as a potential biomarker for CRC is still controversial, although it has been associated with increasingly worse prognosis as the tumor stage advances [35-37]. Downregulation of e-cadherin modulates the WNT/ $\beta$-catenin signaling pathway, which transcribes genes such as c-Myc and cyclin D1 [34,38].

MUC2 is a glycosylated protein that makes up part of the secreted gel-forming mucins [39]. It is normally expressed in the healthy epithelium of the colon but the alteration of MUC2 expression of tumor cells may play an important role in tumor progression. It has been suggested that the level of expression is lower in CRC [40-42], specifically in the early-stage setting [43,44]. Furthermore, low expression was significantly associated with lymph node metastasis, poor cellular differentiation, and advanced tumor stage in CRC [45], while retaining normal expression with improved outcomes [46]. Epithelial growth factor (EGF) and TGF- $\alpha$ seem to play a role in regulating MUC2 expression trough RAS kinases.

Homeobox protein CDX2 is expressed in early intestinal development and is involved in regulating the proliferation and differentiation of intestinal epithelial cells. It is expressed in the nuclei of epithelial cells in the intestinal tract [47]. CDX2 loss of expression has been primarily documented in poorly differentiated advanced intestinal carcinomas as a biomarker of poor prognosis [48-51]. Recent publications have reported the lack of expression of CDX2 as a predictive biomarker, with independence of MSI status [50,52,53].

Given the above, the objectives of the current analysis were to assess the abovementioned biomarkers on the basis of a molecular characterization of early-stage colon cancer patients and to propose a novel IHC biomarker panel with prognostic capabilities. The proposed panel should ideally be based on a robust and standardized assessment methodology, so that it may easily be implemented in hospitals and laboratories with immunohistochemical experience.

We hypothesize that the expression of PD-L1, GLUT-1, e-cadherin, MUC2, and CDX2, in addition to the MMR proteins in tumor samples, can help create an IHC biomarker panel that is able to discern patient prognosis in early-stage colon cancer.

\section{Materials and Methods}

This study follows up on previously published work [54]. It was performed in accordance with the World Medical Association Declaration of Helsinki and was approved by the Regional Clinical Research Ethics Committee (CEIC) Pyto2017/51 Cod. MOL_CRC, 15 May 2018. Patient consent was waived due to the use of stored tumor samples for research purposes, in compliance with current Spanish and European Union legislation (resolutions 1387/2017 $(08 / 11)$ and 193/2018 (06/03) of the Navarra Health Service-Osasunbidea).

A cohort of 162 patients diagnosed with stage II/III CRC at the Hospital Complex of Navarra between 2009 and 2013 underwent surgery with curative intent, and samples were obtained. Tumors were classified according to the TNM Classification of Malignant Tumors, seventh edition [55]. Patients were followed up until 1 October 2018. Their data were anonymized and analyzed in the Department of Pathology. Patients with insufficient tumor material, who were lost to follow-up for more than 3 years, who had fewer than two evaluable IHC-stained blocks, who were missing baseline characteristics, or whose tumor was located rectally were excluded from the analysis.

A cohort of 144 patients with stage II/III colon carcinoma (CC) were included in the study for analysis. Tissue microarrays (TMA) were constructed, stained, revealed, and digitalized as previously described [54]. TMA sections were immunohistochemically stained against PD-L1, GLUT-1, e-cadherin, MUC2, CDX2, and MMR proteins. 
The antibodies used for each biomarker were anti-PD-L1 (SP142; RTU; Roche, Tucson, AZ, USA), anti-GLUT-1 (Clone SMP498; 1:200; Thermo Fisher Scientific, Waltham, MA, USA), anti-e-cadherin (Clone 36; RTU; Roche, Tucson, AZ, USA), anti-MUC2 (Clone CCP58; 1:50; Dako, Glostrup, Denmark), and anti-CDX2 (Clone PA0535; RTU; Novocastra, Newcastle, UK). The MMR proteins used to determine MMR status were MLH1 (Clone PA0610; RTU; Biocare, Pacheco, CA, USA), MSH2 (Clone FE-11; 1:100; Calbiochem, San Diego, CA, USA), MSH6 (Clone PM265AA; RTU; Biocare, Pacheco, CA, USA), and PMS2 (Clone PM344AA; RTU; Biocare, Pacheco, CA, USA). Immunostaining was performed with Vision Leica Biosystems' Bond-Max automatic immunostainer or Roche's BenchMark XT Ventana automatic immunostainer with the OptiView DAB detection and amplification kit.

\subsection{Immunohistochemical Assessment and Scoring}

The most consistent methodology for IHC assessment and scoring for each antibody, in the current or a similar setting, was established from a review of the literature. Each array was assessed by one expert pathologist and one trained senior scientist. When found, discrepancies were evaluated and resolved by a third expert pathologist. All three evaluators were blinded to the patients' clinical data and outcomes.

GLUT-1 is not usually expressed in normal colonic epithelium; however, when there is pathological expression, it is localized in the cytoplasm, mainly in the membrane [30,31,56-58]. Scoring is based on the percentage of expression in the cytoplasm or membrane as described in similar studies [31,59-61]. Absence of expression of GLUT-1 was scored as 0 , expression in fewer than $30 \%$ of the cells of the sample was scored as 1 , expression in $30 \%$ to fewer than $50 \%$ was scored of the cells of the sample as 2, expression in more than $50 \%$ but not more than $90 \%$ of the cells on the sample was scored as 3, and expression in more than $90 \%$ of the cells of the sample was scored as 4 . GLUT- 1 low expression was concluded for scores of 2 or more, and GLUT-1 high expression was ascribed for scores of 3 or more and was considered positive for statistical purposes.

E-cadherin is normally expressed in the membrane, and its loss of expression leads to it being assessed as abnormal $[33,62]$. Scoring is based on stain intensity $(0-3)$ multiplied by the percentage of expression (0-4), rendering a final score between 0 and 12 [35,43]. Stain intensity was scored as absent (0), weak (1), moderate (2), and strong (3). The percentage expression was scored as complete absence (0), <10\% (1), 10-50\% (2), $>50-80 \%(3)$, and $>80 \%$ (4) of tumor cells. Loss of e-cadherin expression was concluded for final scores of $\leq 6$ and was considered positive for statistical purposes.

MUC2 is normally expressed in the perinuclear cytoplasm of the goblet cells in normal colonic mucosa, but expression may vary in tumor cells $[42,43,63,64]$. The scoring is based on the percentage of expression in tumor cells [63-66]. Percentage expression was scored 0 for values of $<25 \%, 1$ for values between $25 \%$ and $<50 \%$, and 2 for values of $\geq 50 \%$ of the tumor cells. MUC2 was considered as retained expression for a score of 2 and loss of expression for a score of 0 or 1 . Loss of expression was considered positive for statistical purposes.

CDX2 is expressed in the nucleus of normal colonic mucosa [67]. Scoring is based on the percentage of tumor cell expression, with a score of 0 for values of $<50 \%, 1$ for values between $50 \%$ and $<95 \%$, and 2 for values $\geq 95 \%[52,53,68,69]$. CDX2 was considered as retained expression for scores of 2 and loss of expression for a score of 0 or 1 . Loss of expression was considered positive for statistical purposes.

MMR proteins and PD-L1 expression were assessed in accordance with a previously published methodology [54].

A summarized methodology for assessment and scoring can be found in Table S1. Scanned images and examples of scoring assessment for each biomarker are presented in Figure S1.

\subsection{Statistical Analysis}

Baseline characteristics and study variable frequencies were summarized as percentages and means. MMR-deficient (dMMR) and MMR-proficient (pMMR) status groups were 
compared using the $t$-test or Mann-Whitney $U$ test depending on the nature and normality of the variables and using the chi-squared test or Fisher's exact test for categorical ones, depending on whether the expected number of cases was over five for all cells in the contingency table or not.

Overall survival (OS) was defined as time from surgery to death due to any cause. Disease-free survival (DFS) was defined as time from surgery to relapse or death due to any cause. Kaplan-Meier curves were used to graphically represent OS and DFS for study variables. The biomarker panel was then assessed with the log-rank test. Univariate and multivariate Cox regression models were also fitted for all variables, and crude hazard ratios (HRs) with 95\% confidence intervals (CIs) were obtained for both outcomes.

The biomarker panel was constructed on the basis of variables that were statistically significant in previous analyses of OS and DFS. Univariate and multivariate Cox regression models were then fitted to the biomarker panel, including known risk factors, such as age and TNM stage, as covariates. Adjusted HRs were obtained for the biomarker panel, and the likelihood ratio test was used to assess its contribution to the model. Lastly, Harrell's $C$ index (crude and adjusted) for survival models was estimated to assess the predictive ability of the biomarker panel for OS and DFS. A value of 0.7 or higher was considered to indicate good discriminative ability.

All analyses were conducted using $\mathrm{R}$, version 3.6.3.

\section{Results}

The final analysis included 144 patients (46 females and 98 males) with early-stage sporadic CC. The mean age at diagnosis was 72.2 years. A small majority of the cases $(79,54.9 \%)$ were right-sided tumors, most were of a high ( $\geq 50 \%$ gland forming) differentiation grade $(118,81.9 \%)$, with a similar split between stage II $(55.6 \%)$ and stage III $(44.4 \%)$ cases, and with an average of 6.7 resected lymph nodes at surgery. Eighteen patients (12.5\% of the entire cohort) belonged to the CMS1 subgroup, $117(81.2 \%)$ belonged to the CMS2/3 subgroup, and nine (6.2\%) belonged to the CMS4 subgroup. Lymphatic vascular, blood vessel, and perineural invasion was found in $36(25 \%), 42$ (29.2\%), and 32 (22.2\%) patients, respectively. Baseline characteristics are presented in Table 1.

The incidence of dMMR was $12.5 \%$. PD-L1 low expression was found in 80 patients (55.6\%), GLUT-1 high expression was found in 81 patients $(68.1 \%)$, loss of expression of e-cadherin was found in 66 patients $(45.8 \%)$, loss of expression of MUC2 was found in 123 patients (85.4\%), and loss of expression of CDX2 was found in 16 patients (11.1\%). Expression of PD-L1 and MUC2 and loss of expression of CDX2 were significantly more frequently found in dMMR tumors.

The incidence of immunohistochemical characteristics is presented in Table 2. The baseline characteristics by MMR subgroup are shown in Table S2.

\subsection{Study Variable Assessment}

dMMR patients had the best prognosis in this cohort [54]. dMMR was, therefore, considered as a standalone first biomarker to be included in the panel. PD-L1, GLUT-1, e-cadherin, MUC2, and CDX2 were subsequently assessed for the rest of the cohort.

The relationship of OS and DFS with the study variables was assessed through univariate Cox regression and graphically represented with Kaplan-Meier curves and the log-rank test. PD-L1-L and GLUT-1-H significantly separated patients with the best and worst prognosis for both outcomes (Table 3 and Figure 1). PD-L1-L and GLUT-1-H resulted in a statistically significant difference in the univariate Cox regression model for OS $(\mathrm{HR}=0.47,95 \% \mathrm{CI}(0.26-0.84), p=0.010$ and HR $=1.94,95 \% \mathrm{CI}(1.05-3.58), p=0.029$, respectively). Similar results were obtained for DFS. CDX2 was near statistical significance for DFS (HR = 2.15, 95\% CI $(0.92-5.04), p=0.070)$. No significant differences were found for the other study variables. 
Table 1. Baseline characteristics.

\begin{tabular}{|c|c|}
\hline Characteristics & $\begin{array}{c}N(\%) \\
n=144\end{array}$ \\
\hline Age * (years) & $72.2(9.6)$ \\
\hline Range & 48-93 \\
\hline \multicolumn{2}{|l|}{ Gender } \\
\hline Female & $46(31.9)$ \\
\hline Male & $98(68.1)$ \\
\hline \multicolumn{2}{|l|}{ Localization } \\
\hline Left & $65(45.1)$ \\
\hline Right & $79(54.9)$ \\
\hline \multicolumn{2}{|l|}{ Differentiation grade } \\
\hline$<50 \%$ & $26(18.1)$ \\
\hline$\geq 50 \%$ & $118(81.9)$ \\
\hline \multicolumn{2}{|l|}{ Lymph node ratio } \\
\hline Mean* $(\mathrm{SD})$ & $6.7(12.1)$ \\
\hline \multicolumn{2}{|l|}{ Histologic type } \\
\hline Colloid & $18(12.5)$ \\
\hline Adenocarcinoma NOS & $125(86.8)$ \\
\hline Signet ring cell carcinoma & $1(0.7)$ \\
\hline \multicolumn{2}{|l|}{ TNM Stage } \\
\hline II & $80(55.6)$ \\
\hline III & $64(44.4)$ \\
\hline \multicolumn{2}{|l|}{ CMS } \\
\hline CMS1 & $18(12.5)$ \\
\hline $\mathrm{CMS} 2 / 3$ & $117(81.2)$ \\
\hline CMS4 & $9(6.2)$ \\
\hline \multicolumn{2}{|l|}{ Lymphatic vascular invasion } \\
\hline Negative & $108(75.0)$ \\
\hline Positive & $36(25.0)$ \\
\hline \multicolumn{2}{|l|}{ Blood vessel invasion } \\
\hline Negative & $102(70.8)$ \\
\hline Positive & $42(29.2)$ \\
\hline \multicolumn{2}{|l|}{ Perineural invasion } \\
\hline Negative & $112(77.8)$ \\
\hline Positive & $32(22.2)$ \\
\hline
\end{tabular}

*Values are means. SD: standard deviation; CMS: consensus molecular subtype; NOS: not otherwise specified.

Table 2. Immunohistochemical characteristics.

\begin{tabular}{|c|c|c|c|c|}
\hline Variable & $\begin{array}{c}n=144 \\
\text { Total N (\%) }\end{array}$ & $\begin{array}{c}n=126 \\
\operatorname{pMMR} N(\%)\end{array}$ & $\begin{array}{c}n=18 \\
\text { dMMR } N(\%)\end{array}$ & $p$ \\
\hline \multicolumn{5}{|l|}{ PD-L1 } \\
\hline PD-L1-H $(\mathrm{p} / \mathrm{n})$ & $29(20.1) / 115$ (79.9) & $19(15.1) / 107$ (84.9) & $10(55.6) / 8(44.4)$ & $<0.001^{1}$ \\
\hline PD-L1-L (p/n) & $80(55.6) / 64(44.4)$ & $66(52.4) / 60(47.6)$ & $14(77.8) / 4(22.2)$ & $0.076^{2}$ \\
\hline \multicolumn{5}{|l|}{ GLUT-1 } \\
\hline GLUT-1-H (p/n) & $81(56.2) / 63(43.8)$ & $70(55.6) / 56(44.4)$ & $11(61.1) / 7$ (38.9) & $0.849^{2}$ \\
\hline GLUT-1-L (p/n) & $98(68.1) / 46(31.9)$ & $86(68.3) / 40(31.7)$ & $12(66.7) / 6(33.3)$ & $1.000^{2}$ \\
\hline \multicolumn{5}{|l|}{ e-Cadherin } \\
\hline Positive & $66(45.8)$ & $56(44.4)$ & $10(55.6)$ & \\
\hline Negative & $78(54.2)$ & $70(55.6)$ & $8(44.4)$ & $0.527^{2}$ \\
\hline \multicolumn{5}{|l|}{ MUC2 } \\
\hline Negative & $21(14.6)$ & $13(10.3)$ & $8(44.4)$ & $0.001^{1}$ \\
\hline \multicolumn{5}{|l|}{ CDX2 } \\
\hline Positive & $16(11.1)$ & $9(7.1)$ & $7(38.9)$ & \\
\hline Negative & $128(88.9)$ & $117(92.9)$ & $11(61.1)$ & $0.001^{1}$ \\
\hline
\end{tabular}

\footnotetext{
${ }^{1}$ Fisher's exact test; ${ }^{2}$ chi-squared test; L: low, H: high; p/n: positive/negative; $\mathrm{p} /$ dMMR: proficient/deficient mismatch repair status.
} 
Table 3. Univariate Cox regression for study variables.

\begin{tabular}{|c|c|c|c|c|}
\hline Variable & Overall Survival HR & $p$ & $\begin{array}{l}\text { Disease-Free } \\
\text { Survival HR }\end{array}$ & $p$ \\
\hline \multicolumn{5}{|l|}{ PD-L1 } \\
\hline PD-L1-H & $0.45(0.16-1.25)$ & 0.088 & $0.46(0.18-1.15)$ & 0.090 \\
\hline PD-L1-L & $0.47(0.26-0.84)$ & 0.010 & $0.47(0.27-0.81)$ & 0.007 \\
\hline \multicolumn{5}{|l|}{ GLUT-1 } \\
\hline GLUT-1-H & $1.94(1.05-3.58)$ & 0.029 & $1.77(1.01-3.09)$ & 0.043 \\
\hline GLUT-1-L & $1.62(0.83-3.19)$ & 0.143 & $1.48(0.81-2.73)$ & 0.201 \\
\hline \multicolumn{5}{|l|}{ e-Cadherin } \\
\hline $\mathrm{N} / \mathrm{P}$ & $1.22(0.69-2.16)$ & 0.497 & $1.06(0.62-1.81)$ & 0.825 \\
\hline $\mathrm{N} / \mathrm{P}$ & $1.05(0.41-2.65)$ & 0.921 & $0.83(0.33-2.09)$ & 0.693 \\
\hline CDX2 & $1.70(0.67-4.31)$ & 0.300 & $2.15(0.92-5.04)$ & 0.070 \\
\hline
\end{tabular}

Reference; N: negative; P: positive; HR: hazard ratio.
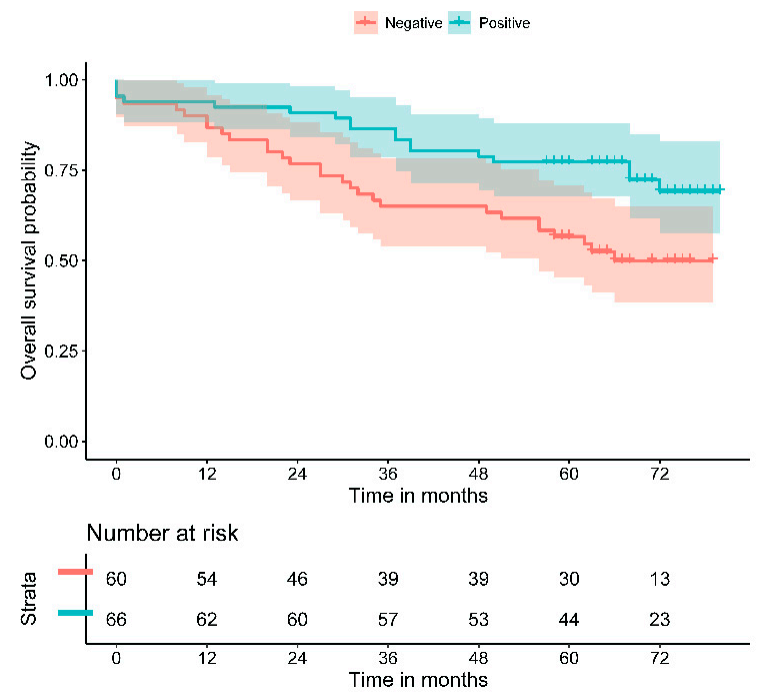

(a)
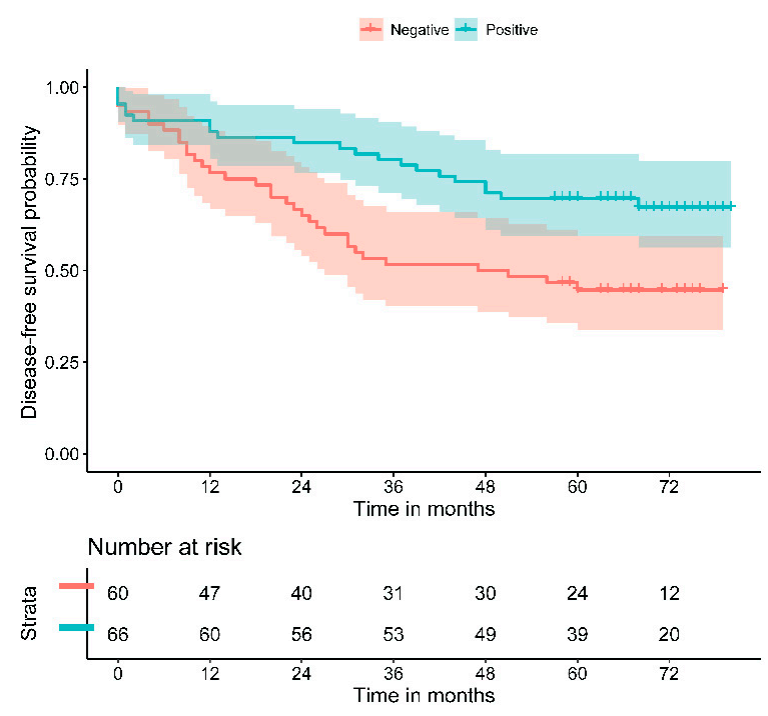

(c)

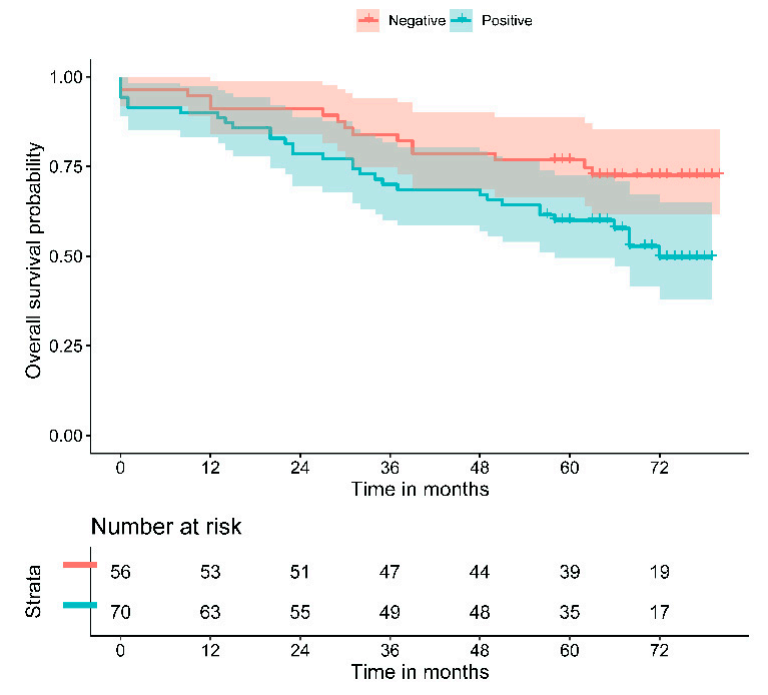

(b)

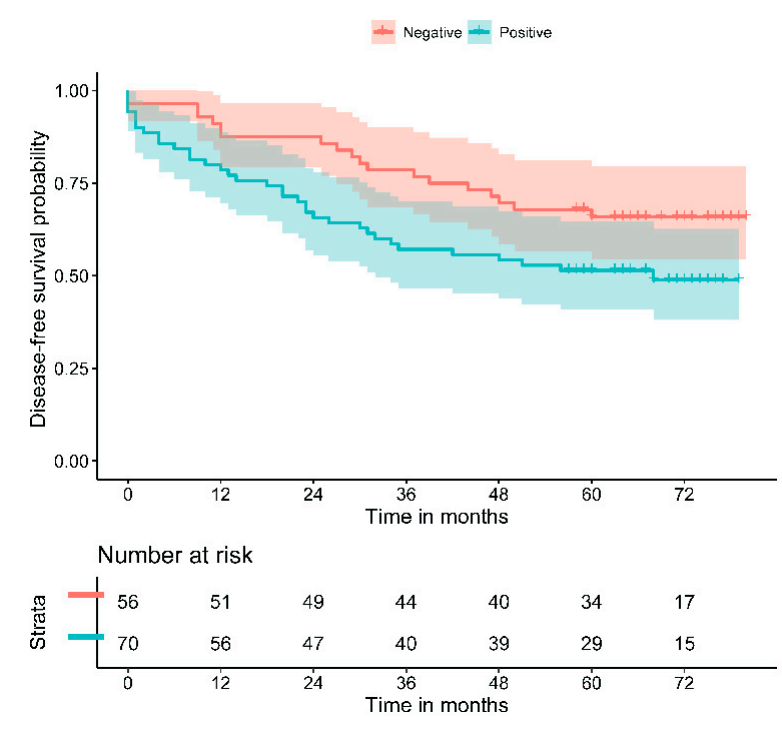

(d)

Figure 1. Kaplan-Meier curves of (a) PD-L1—L and (b) GLUT-1—H for overall survival and of (c) PD-L1-L and (d) GLUT-1—H for disease-free survival. 
Kaplan-Meier curves for all study variables are presented in Figure S2 for OS and Figure S3 for DFS.

In the univariate Cox regression analysis of baseline characteristics (Table S3), for OS, the risk of death rose by $7 \%$ with each additional year of age $(\mathrm{HR}=1.07,95 \% \mathrm{CI}$ $(1.03-1.1), p<0.001)$ and was the only statistically significant baseline characteristic. The risk of relapse or death also significantly increased by $4 \%$ per additional year of age, while perineural invasion increased the risk of relapse or death significantly $(\mathrm{HR}=1.88$, $95 \%$ CI (1.05-3.34), $p=0.032)$. Consistent results were found for DFS. These variables were, therefore, considered in the multivariate analyses.

A multivariate Cox regression analysis was performed to assess for independence of variables found to be statistically significant in the previous analyses. The multivariate results were consistent with the univariate analyses. For OS, expression of PD-L1-L and GLUT- $1-\mathrm{H}$ was statistically significant and independent, conferring a $52 \%$ reduction in the risk of mortality $(\mathrm{HR}=0.48,95 \% \mathrm{CI}(0.27-0.87), p=0.016)$ and almost twice the risk of mortality $(\mathrm{HR}=1.94,95 \% \mathrm{CI}(1.04-3.61), p=0.036)$ respectively; similar results were found for DFS. Adding the loss of expression of CDX2 to the multivariate model showed it to have a tendency toward significance as increased risk of death (HR $=2.74,95 \% \mathrm{CI}(0.96-7.84)$, $p=0.061)$, and it was statistically significant for risk of death or relapse ( $\mathrm{HR}=2.77,95 \% \mathrm{CI}$ $(1.06-7.23), p=0.037)$.

\subsection{Biomarker Panel and Risk Category Definition}

Taking into account the above, MMR, PD-L1-L, and GLUT-1-H were considered in the biomarker panel construction. The risk categories were defined as low-risk when PD-L1 $-\mathrm{L}=$ positive and GLUT-1 $-\mathrm{H}=$ negative or dMMR, high-risk when PD-L1- $\mathrm{L}=$ negative and GLUT-1 $-\mathrm{H}=$ positive, and medium-risk for any other combinations.

Despite the very small number of events, CDX2 showed a trend toward statistical significance for worse prognosis; thus, an exploratory sensitivity analysis was conducted. The loss of expression of CDX2 was added to the high-risk category of the biomarker panel, and the same analysis was performed as for the previous panel.

\subsection{Assessing the Prognositic Capabilities of the Biomarker Panel}

Regression models were derived, and survival was evaluated for the risk categories of the biomarker panel (Table 4 and Figure 2). The biomarker panel divided those patients with low, medium, and high risk of mortality and disease-free survival, independently of age, sex, TNM stage, and perineural invasion. According to the multivariate analysis, patients showing a lack of expression of PD-L1 and a high level of GLUT-1 expression have almost four times the risk of mortality ( $\mathrm{HR}=3.79,95 \% \mathrm{CI}(1.73-8.32), p=0.001)$ of patients with the opposite types of expression or with dMMR. Similar results were found for DFS. These results were consistent with the survival analysis, as illustrated by the Kaplan-Meier curves. The multivariate model also showed that age and perineural invasion were independently associated with a significantly increased risk of mortality $(p=0.017)$.

The likelihood test was performed for the biomarker panel and its risk categories. It showed statistical significance in the univariate and multivariate Cox models for both OS ( $p=0.002$ and $p=0.002$, respectively) and DFS ( $p=0.001$ and 0.003 , respectively).

The goodness of fit for the risk scores was evaluated with Harrell's $C$ index. The scores from the multivariate analyses for OS and DFS were significant, with $C$ values of 0.756 and 0.714 , respectively.

Kaplan-Meier curves for the biomarker panel, by risk category, for OS and DFS both illustrated a statistically significant log-rank test $(p=0.002$ and $p=0.001$, respectively).

The exploratory sensitivity analysis that added CDX2 to the biomarker panel more clearly differentiated patients with higher risk and worse prognosis. Results from the multivariate analysis showed an increased risk of mortality or relapse (HR $=3.94,95 \% \mathrm{CI}$ $(1.82-8.54), p<0.001$ for OS and HR $=3.63,95 \%$ CI (1.78-7.41), $p<0.001$ for DFS). The log-rank test and Kaplan-Meier curves were consistent with these results (Figure S4). 
Table 4. Regression models for risk classification in proposed biomarker panel.

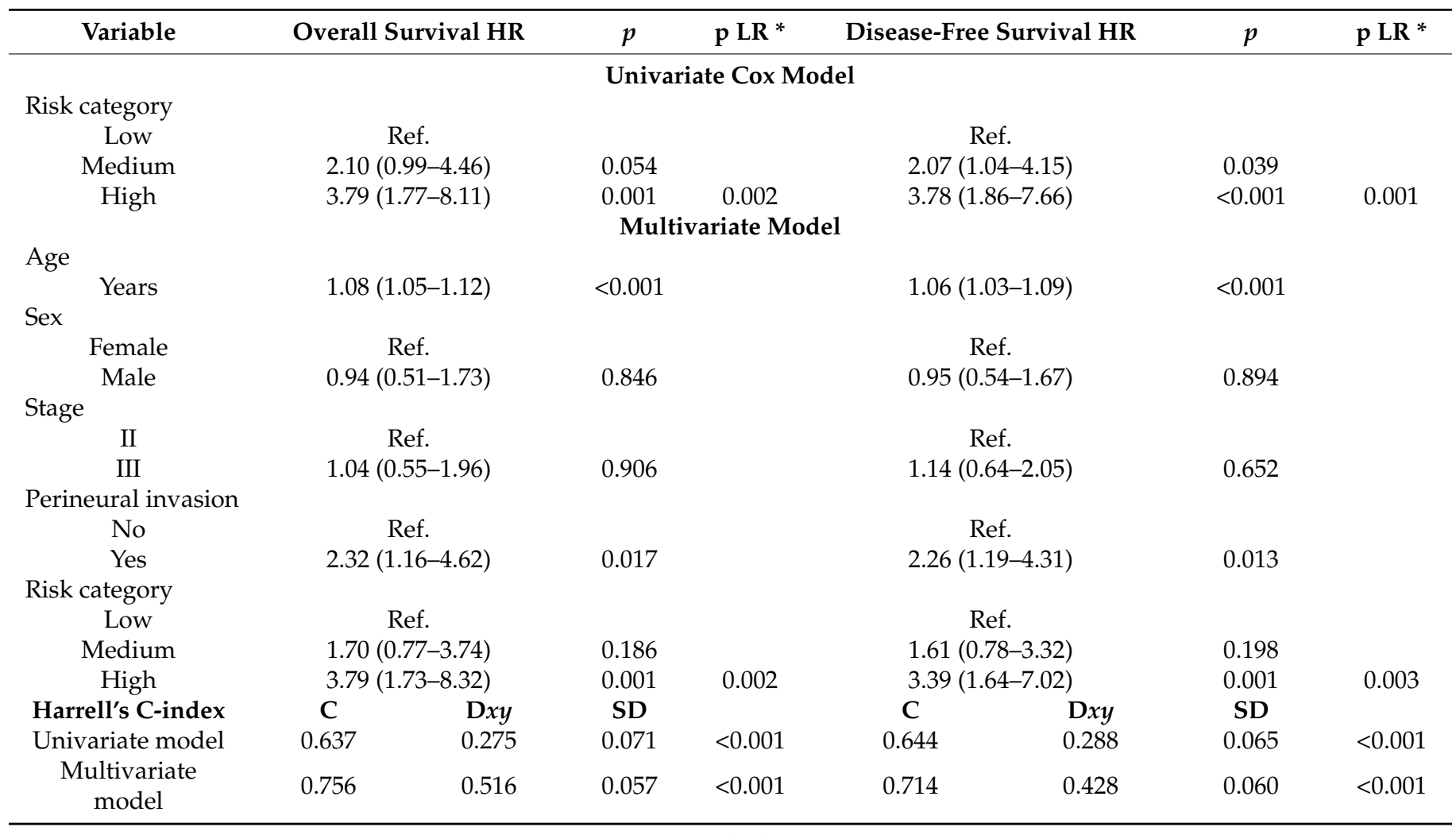

${ }^{*}$ LR: likelihood ratio test; Ref: reference; HR: hazard ratio.

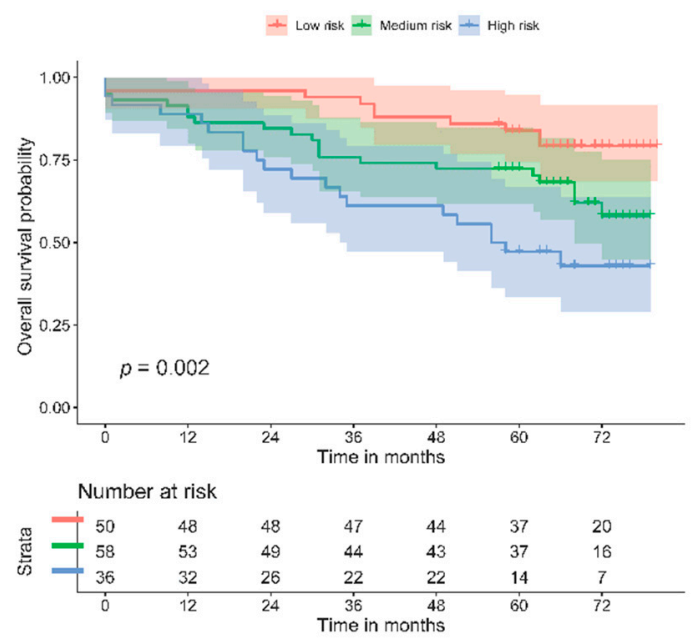

(a)

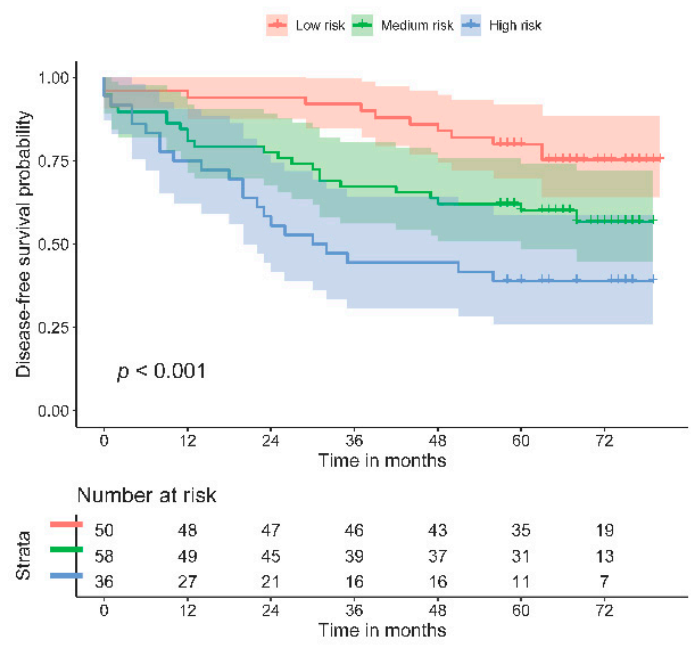

(b)

Figure 2. Kaplan-Meier curves for biomarker panel and risk categories: (a) OS; (b) DFS.

\section{Discussion}

In the present study, we found a selected biomarker panel in a cohort of early-stage CC patients to have significant prognostic value. dMMR, PD-L1, and GLUT-1 provided clearer predictions of the evolution of the disease in these patients. Expression of PD-L1 was significantly associated with longer survival and DFS, while GLUT-1 was significantly associated with poor OS and DFS. The biomarker panel was independent of sex, age, TNM stage, and perineural invasion. The final addition of patients with a loss of CDX2 expression to the high-risk category improved the numerical outcomes of the overall panel. 
This also helps clarify the outcomes for the few well-differentiated tumors that undergo this loss of expression and that have poor overall prognosis. To our knowledge, this is the first biomarker panel that successfully characterizes the prognosis of patients in early-stage colon cancer.

Colorectal cancer tumor biology and evolution vary greatly depending on various intrinsic and extrinsic factors, namely, type of tumor, localization, and stage $[4,7]$. To homogenize the population, we firstly focused on post curative-intent surgery stage II and III colorectal cancers. Secondly, formalin-fixed paraffin-embedded tissue samples from surgery had to be available for study. Thirdly, we excluded rectal cancers due to their different therapeutic approaches, etiology, biology, and prognosis [70-74]. Lastly, all patients had to be followed by the same treatment protocol established by the Colorectal Committee of our center.

Biomarkers were selected on the basis of their biological plausibility and the lessons learned through molecular characterization, especially by the CMS. In addition, it had to be possible to assess them by immunohistochemistry.

Arguably, the most important biomarker identified to date in CC is MSI/dMMR. It has a significant role as a predictive and prognostic tool for analyzing therapeutic response and clinical outcome. MSI is present in almost all proposed classifications, and it is currently assessed by MMR proteins through IHC in clinical practice and across tumor types. Assessing the expression of the MLH1, MSH2, MSH6, and PMS2 proteins, alongside BRAF, is currently helping to identify MSI or dMMR with clinical implications $[4,7,8]$. MSI is found mainly in the CMS1 subtype, since it is characterized by immune infiltration and activation [75]. Overall MSI convenes a good prognosis in the pre-metastatic stage, and its predictive capability has been reported along with targeted therapeutic options underway [76,77].

In our study, PD-L1 was expressed exclusively in immune cells found in either tumorinfiltrating cells or peritumoral area, where it provided a better prognosis for both OS and DFS. This is analogous to MSI tumors, which are enriched with CD3, CD4, CD20, and CD68 in the peritumoral region relative to MSS tumors, and which have also yielded a better prognosis [78]. Immune activation is the hallmark of CMS1; peritumoral immune cells can also be found in CMS3 although in lower quantities, along with expression of immune checkpoint inhibitors [75]. A previous study concluded that the prognostic capabilities of PD-L1, assessed by IHC in early-stage CC, make it possible to differentiate patients in the CMS2/3 subgroup [54].

When the high level of expression of GLUT-1 was assessed, it was mostly found in the membrane, and this indicated a poor prognosis. Metabolic dysregulation, particularly glucose metabolism dysregulation, is considered to be hallmark of the CMS3 subtype [13]. As previously suggested, the expression of GLUT-1 and its influence on prognosis may be a manifestation of tumor hypoxia. Consequently, the adaptive upregulation of aerobic glycolysis may be promoting tumor cell survival [79].

Although e-cadherin and MUC2 were not of prognostic value in our cohort, there seem to be some overlapping biological mechanisms, which may be worth further investigating. E-cadherin is a modulator of the $W N T / \beta$-catenin signaling pathway $[34,38]$. The WNT / $\beta$-catenin pathway is activated in most epithelial tumors, and it is consistently reported, particularly in the CMS2 subtype [80,81]. The pathway is mainly driven by APC mutations [82] and can also be linked to the activation of PD-L1 receptor [22]. The expression of MUC2 is regulated by epithelial growth factor (EGF) and TGF- $\alpha$, and the activation signaling pathway goes through RAS kinases (KRAS, NRAS, and HRAS) [83]. CMS3 or metabolic type is characterized by the presence of KRAS and APC mutations, similarly to GLUT-1.

The expression of CDX2 progressively decreases with the transition from well to poorly differentiated cancer cell lines. This may be why the incidence reported in early-stage CRC is so low and difficult to assess. Regardless, our findings are in line with those of other publications [50,68,84]. As mentioned, the prognostic value of CDX2 is most often described in poorly differentiated tumors, but it is not so clear for well-differentiated or stage II and III 
tumors $[68,85,86]$. Pilati et al. reported that a lack of CDX2 expression in the CMS classification is useful for identifying poor-prognosis patients (CMS4/CDX2-loss), although, consistent with our study, CMS2 and CMS3 tumors rarely show loss of CDX2 [16].

As mentioned above, earlier efforts to implement a CMS classification in a clinical setting have failed, probably due to the robust methodology needed and the lack of prognostic or predictive capabilities, especially with CMS2 and CMS3, which at times comprise more than $50 \%$ of the population [87]. Additionally, in early-stage CC, the number of mesenchymal subtypes (CMS4) is very low, and they sometimes comprise groups with too few events to enable a meaningful statistical analysis $[18,88]$.

These drawbacks are addressed by the proposed biomarker panel in this study. A literature review was performed to determine the adequate and simplest methodology for each biomarker. During the pathological assessment for this study, discrepancies were found in less than $5 \%$ of the samples. The main advantage of IHC may be the wide availability and hospital experience with the technique.

The results of this study suggest that patients should undergo conventional MSI/dMMR assessment in addition to analyzing two or three biomarkers by IHC. Using the specified antibodies in this study, any expression of PD-L1 (>1\%), most of the tissue sample expressing GLUT-1 ( $>50 \%)$, and, if considered relevant, any loss of expression of CDX2 $(<95 \%)$ should be assessed in the course of assembling the biomarker panel. In this way, it was possible to classify approximately one-third of the cohort $(34.7 \%)$ as having a low-risk score and the best prognosis and around one-third of the population (29.9\%) with a high-risk score and the worst prognosis. For the remaining third of patients with medium-risk scores (35.4\%), other clinical variables, such as age, perineural invasion, or tolerance to chemotherapy, could be determining factors when deciding the most appropriate treatment intervention.

For the patients in the low-risk category, observation may be the current preference $[4,7]$. Several clinical trials are currently assessing the predictive value of immune checkpoint inhibitors in dMMR/MSI-H, high tumor mutational burden, or PD-L1-positive CRC patients in early-stage settings, some in phase III (NCT02912559, NCT03827044, NCT04304209, NCT04928807) and several more in phase II, given the encouraging results by Chalabi and colleagues [89]. Overall, either observation or low-level toxicity and personalized/targeted therapies may be preferable to full systemic chemotherapies for these patients.

For the patients in the high-risk category, more aggressive approaches may be considered to complement the upcoming immune checkpoint inhibitors. The addition of 5FU-based systems chemotherapies in combination with platins could prevent tumor progression early on in the process $[4,7]$.

For the patients in the medium-risk category, additional variables may become more relevant when deciding the treatment approach. Other tumor characteristics, such as differentiated or undifferentiated histology, tumor budding, localization, vascular, perineural, or lymphatic invasion, and other patient characteristics, such as age, performance status, or tolerability to systemic treatments, might be the decisive factors for an early aggressive treatment.

The major limitations of this study are its retrospective and single-center nature. We acknowledge some others; even if patients were diagnosed and followed by the same oncology committee, there could be a lack of homogeneity among treatments during the patient journey, which could have influenced the study events. To diminish the impact of low-mortality events, DFS was assessed in parallel with OS, as it has shown to be a good indicator when mortality events are limited. However, the results obtained were consistent for the two outcomes. Since our cohort comprised mainly well-differentiated tumors, CDX2 events were rare and not enough to enable meaningful assessment. Few prognostic parameters have been acknowledged in the ESMO or NCCN guidelines; however, there is still a lack of robust evidence to support their value in all early-stage colorectal cancer patients, and they are limited to specific populations. These parameters were assessed in the present study, but the population in which they were assessed differs from our own, 
because, for the aforementioned reasons, we excluded patients with rectal cancer diagnosis and limited the cohort solely to patients with stage II and III colon cancer. Lastly, although specific antibodies may not be available in certain regions, and original clones may vary, a consistent assessment methodology should nevertheless be pursued.

Multicenter prospective studies could validate the proposed biomarker panel to clarify the prognosis of patients with early-stage CC. Additionally, larger cohorts could confirm its prognostic value and elucidate the effect and value of CDX2 as a complementary element to this biomarker panel.

\section{Conclusions}

In conclusion, this study provides a critical basis for the future development of an accessible IHC assessment capable of accurately describing the prognosis of patients with early-stage CC. The proposed biomarker panel may assist with personalization of treatment in the clinical setting and improve survival outcomes.

Supplementary Materials: The following are available online at https:/ / www.mdpi.com/article/10 .3390/ cancers13235909/s1. Table S1: Summarized methodology for assessment and scoring; Table S2: Baseline characteristics by MMR subgroup; Table S3: Univariate Cox regression in baseline characteristics; Figure S1: Scanned images and example of scoring assessment; Figure S2: Kaplan-Meier curves for overall survival; Figure S3: Kaplan-Meier curves for disease-free survival; Figure S4: Kaplan-Meier curves for biomarker panel and risk categories including CDX2.

Author Contributions: Conceptualization, P.A. and M.L.G.-D.; methodology, P.A., M.L.G.-D. and B.I.-B.; software, B.I.-B. and D.G.S.; validation, D.G.S.; formal analysis, P.A., M.M. and R.V.; investigation, P.A., M.L.G.-D. and I.E.; resources, R.V. and M.M.; data curation, B.I.-B., M.M. and D.G.S.; writing—original draft preparation, P.A. and I.E.; writing—review and editing, P.A., I.E., D.G.S. and R.V.; visualization, R.V. and I.E.; supervision, M.L.G.-D. and P.A.; project administration, M.L.G.-D. and I.E.; funding acquisition, D.G.S. and M.L.G.-D. All authors read and agreed to the published version of the manuscript.

Funding: This research was partly funded by European Union Regional Development Fund (17-20, RefBioII, Trans-Pyrenean cooperation network program 2016-2018, INTERREG-POCTEFA) https: / /ec. europa.eu/regional_policy/en/funding/erdf/, accessed date: 29 August 2021.

Institutional Review Board Statement: The study was approved by the Regional Clinical Research Ethics Committee (CEIC) Pyto2017/51 Cod. MOL_CRC, 15 May 2018.

Informed Consent Statement: Patient consent was waived due to usage of stored tumor samples for research purposes in compliance with the current Spanish and European Union legislation (resolution 1387/2017 (08/11) and resolution 193/2018 (06/03) of the Navarra Health Service-Osasunbidea).

Data Availability Statement: Full data for this study are available from the corresponding authors upon request.

Acknowledgments: We want to thank Lilia Aizkorbe for providing insight and for critical reading. Medical writing assistance was provided by Phil Mason.

Conflicts of Interest: P.A. is an employee of Servier Medical Affairs, although there were no affiliations or financial involvement with this or any other organization or entity, with financial or scientific interest, or with the subject matter or materials discussed in the manuscript. All other authors declare no conflicts of interest. The funders had no role in the design of the study, in the collection, analyses, or interpretation of data, in the writing of the manuscript, or in the decision to publish the results.

\section{References}

1. Bray, F.; Ferlay, J.; Soerjomataram, I.; Siegel, R.L.; Torre, L.A.; Jemal, A. Global cancer statistics 2018: GLOBOCAN estimates of incidence and mortality worldwide for 36 cancers in 185 countries. CA Cancer J. Clin. 2018, 68, 394-424. [CrossRef]

2. Siegel, R.L.; Miller, K.D.; Jemal, A. Cancer statistics, 2020. CA A Cancer J Clin. 2020, 70, 7-30. [CrossRef] [PubMed]

3. Verkuijl, S.J.; Jonker, J.E.; Trzpis, M.; Burgerhof, J.G.; Broens, P.M.; Furnée, E.J. Functional outcomes of surgery for colon cancer: A systematic review and meta-analysis. Eur. J. Surg. Oncol. (EJSO) 2020, 47, 960-969. [CrossRef] [PubMed]

4. National Comprehensive Cancer Network (NCCN). NCCN Clinical Practice Guidelines in Oncology. Colon Cancer Version 2.2021 [Internet]. 2021. Available online: https:/ / www.nccn.org/professionals/physician_gls/pdf/colon.pdf (accessed on 29 May 2021). 
5. Zhao, B.; Wang, L.; Qiu, H.; Zhang, M.; Sun, L.; Peng, P.; Yu, Q.; Yuan, X. Mechanisms of resistance to anti-EGFR therapy in colorectal cancer. Oncotarget 2017, 17, 3980-4000. [CrossRef] [PubMed]

6. Misale, S.; Di Nicolantonio, F.; Sartore-Bianchi, A.; Siena, S.; Bardelli, A. Resistance to Anti-EGFR Therapy in Colorectal Cancer: From Heterogeneity to Convergent Evolution. Cancer Discov. 2014, 4, 1269-1280. [CrossRef]

7. Argilés, G.; Tabernero, J.; Labianca, R.; Hochhauser, D.; Salazar, R.; Iveson, T.; Laurent-Puig, P.; Quirke, P.; Yoshino, T.; Taieb, J.; et al. Localised colon cancer: ESMO Clinical Practice Guidelines for diagnosis, treatment and follow-up. Ann. Oncol. 2020, 31, 1291-1305. [CrossRef]

8. Andre, T.; Shiu, K.-K.; Kim, T.W.; Jensen, B.V.; Jensen, L.H.; Punt, C.J.A.; Smith, D.M.; Garcia-Carbonero, R.; Benavides, M.; Gibbs, P.; et al. Pembrolizumab versus chemotherapy for microsatellite instability-high/mismatch repair deficient metastatic colorectal cancer: The phase 3 KEYNOTE-177 Study. J. Clin. Oncol. 2020, 38, LBA4. [CrossRef]

9. Sjöblom, T.; Jones, S.; Wood, L.D.; Parsons, D.W.; Lin, J.; Barber, T.D.; Mandelker, D.; Leary, R.J.; Ptak, J.; Silliman, N.; et al. The consensus coding sequences of human breast and colorectal cancers. Science 2006, 314, 268-274. [CrossRef] [PubMed]

10. Jass, J.R. Classification of colorectal cancer based on correlation of clinical, morphological and molecular features. Histopathology 2007, 50, 113-130. [CrossRef]

11. Ogino, S.; Goel, A. Molecular Classification and Correlates in Colorectal Cancer. J. Mol. Diagn. 2008, 10, 13-27. [CrossRef]

12. Roepman, P.; Schlicker, A.; Tabernero, J.; Majewski, I.; Tian, S.; Moreno, V.; Snel, M.H.; Chresta, C.M.; Rosenberg, R.; Nitsche, U.; et al. Colorectal cancer intrinsic subtypes predict chemotherapy benefit, deficient mismatch repair and epithelial-to-mesenchymal transition. Int. J. Cancer 2014, 134, 552-562. [CrossRef] [PubMed]

13. Guinney, J.; Dienstmann, R.; Wang, X.; de Reyniès, A.; Schlicker, A.; Soneson, C.; Marisa, L.; Roepman, P.; Nyamundanda, G.; Angelino, P.; et al. The consensus molecular sub-types of colorectal cancer. Nat. Med. 2015, 21, 1350-1356. [CrossRef] [PubMed]

14. Singh, M.P.; Rai, S.; Pandey, A.; Singh, N.K.; Srivastava, S. Molecular subtypes of colorectal cancer: An emerging therapeutic opportunity for personalized medicine. Genes Dis. 2019, 8, 133-145. [CrossRef] [PubMed]

15. Inamura, K. Colorectal Cancers: An Update on Their Molecular Pathology. Cancers 2018, 10, 26. [CrossRef]

16. Pilati, C.; Taieb, J.; Balogoun, R.; Marisa, L.; de Reyniès, A.; Laurent-Puig, P. CDX2 prognostic value in stage II/III resected colon cancer is related to CMS classification. Ann. Oncol. 2017, 28, 1032-1035. [CrossRef]

17. De Sousa EMelo, F.; Wang, X.; Jansen, M.; Fessler, E.; Trinh, A.; de Rooij, L.P.M.H.; de Jong, J.H.; de Boer, O.J.; van Leersum, R.; Bijlsma, M.F.; et al. Poor-prognosis colon cancer is defined by a molecularly distinct subtype and develops from serrated precursor lesions. Nat. Med. 2013, 19, 614-618. [CrossRef]

18. Fontana, E.; Eason, K.; Cervantes, A.; Salazar, R.; Sadanandam, A. Context matters-Consensus molecular subtypes of colorectal cancer as biomarkers for clinical trials. Ann. Oncol. 2019, 30, 520-527. [CrossRef]

19. Song, N.; Pogue-Geile, K.L.; Gavin, P.G.; Yothers, G.; Kim, S.R.; Johnson, N.L.; Lipchik, C.; Allegra, C.J.; Petrelli, N.J.; O'Connell, M.J.; et al. Clinical Outcome From Oxaliplatin Treatment in Stage II/III Colon Cancer According to Intrinsic Subtypes: Secondary Analysis of NSABP C-07/NRG Oncology Randomized Clinical Trial. JAMA Oncol. 2016, 2, 1162-1169. [CrossRef]

20. Azcue, P.; Mercado Gutierrez, M.; Galbete, A.; Suarez Alecha, J.; Gomez-Dorronsoro, M.L.; Guerrero Setas, D. In Search of an Immunohistochemical Classification of Early Stage Colon Adenocarcinomas, Results of a Tertiary Hospital. In Proceedings of the 32nd Congress of the ESP and XXXIII International Congress of the IAP, Glasgow, UK, 5-9 December 2020; pp. 1-390.

21. Chen, S.; Crabill, G.A.; Pritchard, T.S.; McMiller, T.L.; Wei, P.; Pardoll, D.M.; Pan, F.; Topalian, S.L. Mechanisms regulating PD-L1 expression on tumor and immune cells. J. Immunother. Cancer 2019, 7, 305. [CrossRef]

22. Ruan, Z.; Liang, M.; Lai, M.; Shang, L.; Deng, X.; Su, X. KYA1797K down-regulates PD-L1 in colon cancer stem cells to block immune evasion by suppressing the $\beta$-catenin/STT3 signaling pathway. Int. Immunopharmacol. 2019, 78, 106003. [CrossRef]

23. Shen, Z.; Gu, L.; Mao, D.; Chen, M.; Jin, R. Clinicopathological and prognostic significance of PD-L1 expression in colorectal cancer: A systematic review and meta-analysis. World J. Surg. Oncol. 2019, 17, 1-9. [CrossRef] [PubMed]

24. Duan, J.; Liu, X.; Chen, H.; Sun, Y.; Liu, Y.; Bai, H.; Wang, J. Impact of PD-L1, transforming growth factor- $\beta$ expression and tumor-infiltrating CD8 + T cells on clinical outcome of patients with advanced thymic epithelial tumors: PD-L1, TGF- $\beta$, and CD8 + TILs in TETs. Thorac. Cancer. 2018, 9, 1341-1353. [CrossRef] [PubMed]

25. Lind, H.; Gameiro, S.R.; Jochems, C.; Donahue, R.N.; Strauss, J.; Gulley, J.L.; Palena, C.; Schlom, J. Dual targeting of TGF- $\beta$ and PD-L1 via a bifunctional anti-PD-L1/TGF- $\beta$ RII agent: Status of preclinical and clinical advances. J. Immunother. Cancer 2020, 8 , e000433. [CrossRef]

26. Yi, M.; Zhang, J.; Li, A.; Niu, M.; Yan, Y.; Jiao, Y.; Luo, S.; Zhou, P.; Wu, K. The construction, expression, and enhanced anti-tumor activity of YM101: A bispecific antibody simultaneously targeting TGF- $\beta$ and PD-L1. J. Hematol. Oncol. 2021, 14, 27. [CrossRef] [PubMed]

27. Younes, M.; Lechago, L.V.; Somoano, J.R.; Mosharaf, M.; Lechago, J. Wide Expression of the Human Erythrocyte Glucose Transporter Gluti in Human Cancers. Cancer Res. 1996, 56, 1164-1167. [PubMed]

28. Carvalho, K.C.; Cunha, I.W.; Rocha, R.M.; Ayala, F.R.; Cajaíba, M.M.; Begnami, M.D.; Vilela, R.S.; Paiva, G.R.; Andrade, R.G.; Soares, F.A. GLUT1 expression in malignant tumors and its use as an immunodiagnostic marker. Clinics 2011, 66, 965-972. [CrossRef]

29. Bai, J.; Xu, J.; Zhao, J.; Zhang, R. Downregulation of lncRNA AWPPH inhibits colon cancer cell proliferation by downregulating GLUT-1. Oncol. Lett. 2019, 18, 2007-2012. [CrossRef] [PubMed] 
30. Haber, R.S.; Rathan, A.; Weiser, K.R.; Pritsker, A.; Itzkowitz, S.H.; Bodian, C.; Slater, G.; Weiss, A.; Burstein, D.E. GLUT1 glucose transporter expression in colorectal carcinoma. Cancer 1998, 83, 34-40. [CrossRef]

31. Sakashita, M.; Aoyama, N.; Minami, R.; Maekawa, S.; Kuroda, K.; Shirasaka, D.; Ichihara, T.; Kuroda, Y.; Maeda, S.; Kasuga, M. Glut1 expression in T1 and T2 stage colorectal carcinomas: Its relationship to clinicopathological features. Eur. J. Cancer 2001, 37, 204-209. [CrossRef]

32. Gumbiner, B.M. Cell Adhesion: The Molecular Basis of Tissue Architecture and Morphogenesis. Cell 1996, 84, 345-357. [CrossRef]

33. Christou, N.; Perraud, A.; Blondy, S.; Jauberteau, M.-O.; Battu, S.; Mathonnet, M. E-cadherin: A potential biomarker of colorectal cancer prognosis. Oncol. Lett. 2017, 13, 4571-4576. [CrossRef] [PubMed]

34. Pal, I.; Rajesh, Y.; Banik, P.; Dey, G.; Dey, K.K.; Bharti, R.; Naskar, D.; Chakraborty, S.; Ghosh, S.K.; Das, S.K.; et al. Prevention of epithelial to mesenchymal transition in colorectal carcinoma by regulation of the E-cadherin- $\beta$-catenin-vinculin axis. Cancer Lett. 2019, 452, 254-263. [CrossRef] [PubMed]

35. Kim, J.H.; Kim, C.N.; Kang, D.W. Squalene Epoxidase Correlates E-Cadherin Expression and Overall Survival in Colorectal Cancer Patients: The Impact on Prognosis and Correlation to Clinicopathologic Features. J. Clin. Med. 2019, 8, 632. [CrossRef] [PubMed]

36. Wilmanns, C.; Grossmann, J.; Steinhauer, S.; Manthey, G.; Weinhold, B.; Schmitt-Gräff, A.; Von Specht, B.-U. Soluble serum E-cadherin as a marker of tumour progression in colorectal cancer patients. Clin. Exp. Metastasis 2004, 21, 75-78. [CrossRef] [PubMed]

37. Okugawa, Y.; Toiyama, Y.; Inoue, Y.; Iwata, T.; Fujikawa, H.; Saigusa, S.; Konishi, N.; Tanaka, K.; Uchida, K.; Kusunoki, M. Clinical Significance of Serum Soluble E-cadherin in Colorectal Carcinoma. J. Surg. Res. 2012, 175, e67-e73. [CrossRef] [PubMed]

38. Thievessen, I.; Seifert, H.-H.; Swiatkowski, S.; Florl, A.R.; Schulz, W.A. E-cadherin involved in inactivation of WNT/ $\beta$-catenin signalling in urothelial carcinoma and normal urothelial cells. Br. J. Cancer 2003, 88, 1932-1938. [CrossRef] [PubMed]

39. Toribara, N.W.; Gum, J.R.; Culhane, P.J.; Lagace, R.E.; Hicks, J.W.; Petersen, G.M.; Kim, Y.S. MUC-2 human small intestinal mucin gene structure. Repeated arrays and polymorphism. J. Clin. Investig. 1991, 88, 1005-1013. [CrossRef] [PubMed]

40. Lasota, J.; Chłopek, M.; Lamoureux, J.; Christiansen, J.; Kowalik, A.; Wasag, B.; Felisiak-Gołąbek, A.; Agaimy, A.; Biernat, W.; Canzonieri, V.; et al. Colonic Adenocarcinomas Harboring NTRK Fusion Genes: A Clinicopathologic and Molecular Genetic Study of 16 Cases and Review of the Literature. Am. J. Surg. Pathol. 2020, 44, 162-173. [CrossRef] [PubMed]

41. Kasprzak, A.; Siodła, E.; Andrzejewska, M.; Szmeja, J.; Seraszek-Jaros, A.; Cofta, S.; Szaflarski, W. Differential expression of mucin 1 and mucin 2 in colorectal cancer. World J. Gastroenterol. 2018, 24, 4164-4177. [CrossRef]

42. Elzagheid, A.; Emaetig, F.; Buhmeida, A.; Laato, M.; El-Faitori, O.; Syrjänen, K.; Collan, Y.; Pyrhönen, S. Loss of MUC2 expression predicts disease recurrence and poor outcome in colorectal carcinoma. Tumor Biol. 2013, 34, 621-628. [CrossRef]

43. Kang, H.; Min, B.S.; Lee, K.Y.; Kim, N.K.; Kim, S.N.; Choi, J.; Kim, H. Loss of E-cadherin and MUC2 Expressions Correlated with Poor Survival in Patients with Stages II and III Colorectal Carcinoma. Ann. Surg. Oncol. 2010, 18, 711-719. [CrossRef] [PubMed]

44. Cecchini, M.J.; Walsh, J.C.; Parfitt, J.; Chakrabarti, S.; Correa, R.J.; MacKenzie, M.J.; Driman, D.K. CDX2 and Muc2 immunohistochemistry as prognostic markers in stage II colon cancer. Hum. Pathol. 2019, 90, 70-79. [CrossRef] [PubMed]

45. Wang, H.; Jin, S.; Lu, H.; Mi, S.; Shao, W.; Zuo, X.; Yin, H.; Zeng, S.; Shimamoto, F.; Qi, G. Expression of surviving, MUC2 and MUC5 in colorectal cancer and their association with clinicopathological characteristics. Oncol. Lett. 2017, 14, 1011-1016. [CrossRef]

46. Li, C.; Zuo, D.; Yin, L.; Lin, Y.; Li, C.; Liu, T.; Wang, L. Prognostic Value of MUC2 Expression in Colorectal Cancer: A Systematic Review and Meta-Analysis. Gastroenterol. Res. Pract. 2018, 2018, 1-12. [CrossRef]

47. Werling, R.W.; Yaziji, H.; Bacchi, C.E.; Gown, A.M. CDX2, a Highly Sensitive and Specific Marker of Adenocarcinomas of Intestinal Origin: An Immunohistochemical Survey of 476 Primary and Metastatic Carcinomas. Am. J. Surg. Pathol. 2003, 27, 303-310. [CrossRef] [PubMed]

48. Zhang, B.Y.; Jones, J.C.; Briggler, A.M.; Hubbard, J.M.; Kipp, B.R.; Sargent, D.J.; Dixon, J.G.; Grothey, A. Lack of Caudal-Type Homeobox Transcription Factor 2 Expression as a Prognostic Biomarker in Metastatic Colorectal Cancer. Clin. Color. Cancer 2016, 16, 124-128. [CrossRef]

49. Olsen, J.; Eiholm, S.; Kirkeby, L.; Espersen, M.; Jess, P.; Gögenür, I.; Troelsen, J. CDX2 downregulation is associated with poor differentiation and MMR deficiency in colon cancer. Exp. Mol. Pathol. 2016, 100, 59-66. [CrossRef]

50. Bruun, J.; Sveen, A.; Barros, R.; Eide, P.W.; Eilertsen, I.; Kolberg, M.; Pellinen, T.; David, L.; Svindland, A.; Kallioniemi, O.; et al. Prognostic, predictive, and pharmacogenomic assessments of CDX2 refine stratification of colorectal cancer. Mol. Oncol. 2018, 12, 1639-1655. [CrossRef] [PubMed]

51. Bae, J.M.; Lee, T.H.; Cho, N.-Y.; Kim, T.-Y.; Kang, G.H. Loss of CDX2 expression is associated with poor prognosis in colorectal cancer patients. World J. Gastroenterol. 2015, 21, 1457-1467. [CrossRef]

52. Dalerba, P.; Sahoo, D.; Paik, S.; Guo, X.; Yothers, G.; Song, N.; Wilcox-Fogel, N.; Forgó, E.; Rajendran, P.S.; Miranda, S.P.; et al CDX2 as a Prognostic Biomarker in Stage II and Stage III Colon Cancer. N. Engl. J. Med. 2016, 374, 211-222. [CrossRef]

53. Slik, K.; Turkki, R.; Carpén, O.; Kurki, S.; Korkeila, E.; Sundström, J.; Pellinen, T. CDX2 Loss With Microsatellite Stable Phe-notype Predicts Poor Clinical Outcome in Stage II Colorectal Carcinoma. Am. J. Surg. Pathol. 2019, 43, 1473-1482. [CrossRef] [PubMed]

54. Azcue, P.; Encío, I.; Setas, D.G.; Alecha, J.S.; Galbete, A.; Mercado, M.; Vera, R.; Gomez-Dorronsoro, M. PD-L1 as a Prognostic Factor in Early-Stage Colon Carcinoma within the Immunohistochemical Molecular Subtype Classification. Cancers 2021, 13, 1943. [CrossRef] [PubMed] 
55. Sobin, L.H.; Gospodarowicz, M.K.; Wittekind, C. TNM Classification of Malignant Tumours, 7th ed.; Wiley-Blackwell: Somerset, UK, 2011; 336p.

56. Cooper, R.; Sarioğlu, S.; Sökmen, S.; Füzün, M.; Küpelioğlu, A.; Valentine, H.; Görken, I.B.; Airley, R.; West, C. Glucose transporter-1 (GLUT-1): A potential marker of prognosis in rectal carcinoma? Br. J. Cancer 2003, 89, 870-876. [CrossRef] [PubMed]

57. Jun, Y.J.; Jang, S.M.; Han, H.L.; Lee, K.H.; Jang, K.-S.; Paik, S.S. Clinicopathologic significance of GLUT1 expression and its correlation with Apaf-1 in colorectal adenocarcinomas. World J. Gastroenterol. 2011, 17, 1866-1873. [CrossRef]

58. Madunić, I.V.; Madunić, J.; Breljak, D.; Karaica, D.; Sabolić, I. Sodium-glucose cotransporters: New targets of cancer therapy? Arch. Ind. Hyg. Toxicol. 2018, 69, 278-285. [CrossRef]

59. Airley, R.; Evans, A.; Mobasheri, A.; Hewitt, S. Glucose transporter Glut-1 is detectable in peri-necrotic regions in many human tumor types but not normal tissues: Study using tissue microarrays. Ann. Anat. Anat. Anz. 2010, 192, 133-138. [CrossRef] [PubMed]

60. Yang, J.; Wen, J.; Tian, T.; Lu, Z.; Wang, Y.; Wang, Z. GLUT-1 overexpression as an unfavorable prognostic biomarker in patients with colorectal cancer. Oncotarget. 2017, 8, p. 11788. Available online: http:/ /www.oncotarget.com/fulltext/14352 (accessed on 5 March 2021).

61. Yu, M.; Chen, S.; Hong, W.; Gu, Y.; Huang, B.; Lin, Y.; Zhou, Y.; Jin, H.; Deng, Y.; Tu, L.; et al. Prognostic role of glycolysis for cancer outcome: Evidence from 86 studies. J. Cancer Res. Clin. Oncol. 2019, 145, 967-999. [CrossRef]

62. Jurčić, P.; Radulović, P.; Balja, M.P.; Milosevic, M.; Krušlin, B. E-cadherin and NEDD9 expression in primary colorectal cancer, metastatic lymph nodes and liver metastases. Oncol. Lett. 2019, 17, 2881-2889. [CrossRef]

63. Kesari, M.V.; Gaopande, V.L.; Joshi, A.R.; Babanagare, S.V.; Gogate, B.P.; Khadilkar, A.V. Immunohistochemical study of MUC1, MUC2 and MUC5AC in colorectal carcinoma and review of literature. Indian J. Gastroenterol. 2015, 34, 63-67. [CrossRef]

64. Betge, J.; Schneider, N.I.; Harbaum, L.; Pollheimer, M.J.; Lindtner, R.A.; Kornprat, P.; Ebert, M.P.; Langner, C. MUC1, MUC2, MUC5AC, and MUC6 in colorectal cancer: Expression profiles and clinical significance. Virchows Arch. 2016, 469, 255-265. [CrossRef]

65. Al-Maghrabi, J.; Sultana, S.; Gomaa, W. Low expression of MUC2 is associated with longer disease-free survival in patients with colorectal carcinoma. Saudi J. Gastroenterol. 2019, 25, 61-66. [CrossRef] [PubMed]

66. Imai, Y.; Yamagishi, H.; Fukuda, K.; Ono, Y.; Inoue, T.; Ueda, Y. Differential mucin phenotypes and their significance in a variation of colorectal carcinoma. World J. Gastroenterol. 2013, 19, 3957-3968. [CrossRef] [PubMed]

67. Grainger, S.; Savory, J.G.; Lohnes, D. Cdx2 regulates patterning of the intestinal epithelium. Dev. Biol. 2010, 339, 155-165. [CrossRef] [PubMed]

68. Hansen, T.; Kjær-Frifeldt, S.; Eriksen, A.C.; Lindebjerg, J.; Jensen, L.H.; Sørensen, F.B.; Jakobsen, A. Prognostic impact of CDX2 in stage II colon cancer: Results from two nationwide cohorts. Br. J. Cancer 2018, 119, 1367-1373. [CrossRef]

69. Tomasello, G.; Barni, S.; Turati, L.; Ghidini, M.; Pezzica, E.; Passalacqua, R.; Petrelli, F. Association of CDX2 Expression With Survival in Early Colorectal Cancer: A Systematic Review and Meta-analysis. Clin. Colorectal Cancer 2018, 17, 97-103. [CrossRef] [PubMed]

70. Berger, M.D.; Yang, D.; Sunakawa, Y.; Zhang, W.; Ning, Y.; Matsusaka, S.; Okazaki, S.; Miyamoto, Y.; Suenaga, M.; Schirripa, M.; et al. Impact of sex, age, and ethnicity/race on the survival of patients with rectal cancer in the United States from 1988 to 2012 . Oncotarget 2016, 7, 53668-53678. [CrossRef]

71. Salem, M.E.; Yin, J.; Weinberg, B.A.; Renfro, L.A.; Pederson, L.D.; Maughan, T.S.; Adams, R.; Van Cutsem, E.; Falcone, A.; Tebbutt, N.C.; et al. Clinicopathological differences and survival outcomes with first-line therapy in patients with left-sided colon cancer and rectal cancer: Pooled analysis of 2879 patients from AGITG (MAX), COIN, FOCUS2, OPUS, CRYSTAL and COIN-B trials in the ARCAD database. Eur. J. Cancer 2018, 103, 205-213. [CrossRef] [PubMed]

72. Tamas, K.; Walenkamp, A.M.E.; de Vries, E.G.E.; van Vugt, M.A.T.M.; Beets-Tan, R.G.; van Etten, B.; de Groota, D.J.A.; Hospersa, G.A.P. Rectal and colon cancer: Not just a different anatomic site. Cancer Treat. Rev. 2015, 41, 671-679. [CrossRef] [PubMed]

73. Wyss, J.; Dislich, B.; Koelzer, V.H.; Galván, J.A.; Dawson, H.; Hädrich, M.; Inderbitzin, D.; Lugli, A.; Zlobec, I.; Berger, M.D. Stromal PD-1/PD-L1 Expression Predicts Outcome in Colon Cancer Patients. Clin. Colorectal Cancer 2019, 18, e20-e38. [CrossRef] [PubMed]

74. Van der Sijp, M.P.L.; Bastiaannet, E.; Mesker, W.E.; van der Geest, L.G.M.; Breugom, A.J.; Steup, W.H. Differences between colon and rectal cancer in complications, short-term survival and recurrences. Int. J. Colorectal Dis. 2016, 31, 1683-1691. [CrossRef] [PubMed]

75. Picard, E.; Verschoor, C.P.; Ma, G.W.; Pawelec, G. Relationships between Immune Landscapes, Genetic Subtypes and Responses to Immunotherapy in Colorectal Cancer. Front. Immunol. 2020, 11, 369. [CrossRef]

76. Sun, B.L. Current Microsatellite Instability Testing in Management of Colorectal Cancer. Clin. Colorectal Cancer 2020, 20, e12-e20. [CrossRef]

77. Thomas, J.; Leal, A.; Overman, M.J. Clinical Development of Immunotherapy for Deficient Mismatch Repair Colorectal Cancer. Clin. Colorectal Cancer 2020, 19, 73-81. [CrossRef] [PubMed]

78. De Smedt, L.; Lemahieu, J.; Palmans, S.; Govaere, O.; Tousseyn, T.; Van Cutsem, E.; Prenen, H.; Tejpar, S.; Spaepen, M.; Matthijs, G.; et al. Microsatellite instable vs stable colon carcinomas: Analysis of tumour heterogeneity, inflammation and angiogenesis. Br. J. Cancer 2015, 113, 500-509. [CrossRef] [PubMed]

79. Airley, R.E.; Mobasheri, A. Hypoxic Regulation of Glucose Transport, Anaerobic Metabolism and Angiogenesis in Cancer: Novel Pathways and Targets for Anticancer Therapeutics. Chemotherapy 2007, 53, 233-256. [CrossRef] [PubMed] 
80. Dienstmann, R.; Vermeulen, L.; Guinney, J.; Kopetz, S.; Tejpar, S.; Tabernero, J. Consensus molecular subtypes and the evolution of precision medicine in colorectal cancer. Nat. Rev. Cancer 2017, 17, 79-92. [CrossRef]

81. Najdi, R.; Holcombe, R.F.; Waterman, M.L. Wnt signaling and colon carcinogenesis: Beyond APC. J. Carcinog. 2011, 10, 5. [CrossRef]

82. Juanes, M.A. Cytoskeletal Control and Wnt Signaling-APC's Dual Contributions in Stem Cell Division and Colorectal Cancer. Cancers 2020, 12, 3811. [CrossRef]

83. Perrais, M.; Pigny, P.; Copin, M.-C.; Aubert, J.-P.; Van Seuningen, I. Induction of MUC2 and MUC5AC Mucins by Factors of the Epidermal Growth Factor (EGF) Family Is Mediated by EGF Receptor/Ras/Raf/Extracellular Signal-regulated Kinase Cascade and Sp1. J. Biol. Chem. 2002, 277, 32258-32267. [CrossRef]

84. Nishiuchi, A.; Hisamori, S.; Sakaguchi, M.; Fukuyama, K.; Hoshino, N.; Itatani, Y.; Honma, S.; Maekawa, H.; Nishigori, T.; Tsunoda, S.; et al. MicroRNA-9-5p-CDX2 Axis: A Useful Prognostic Biomarker for Patients with Stage II/III Colorectal Cancer. Cancers 2019, 11, 1891. [CrossRef]

85. Baba, Y.; Nosho, K.; Shima, K.; Freed, E.; Irahara, N.; Philips, J. Relationship of CDX2 Loss with Molecular Features and Prognosis in Colorectal Cancer. Clin. Cancer Res. 2009, 15, 4665-4673. [CrossRef]

86. Dae Hong, K.; Lee, D.; Lee, Y.; Lee, S.I.; Moon, H.Y. Reduced CDX2 Expression Predicts Poor Overall Survival in Patients with Colorectal Cancer. Am. Surgeon. 2013, 79, 353-360. [CrossRef]

87. Trinh, A.; Trumpi, K.; De Sousa EMelo, F.; Wang, X.; de Jong, J.H.; Fessler, E. Practical and Robust Identification of Molecular Subtypes in Colorectal Cancer by Immunohistochemistry. Clin. Cancer Res. 2017, 23, 387-398. [CrossRef] [PubMed]

88. Purcell, R.V.; Schmeier, S.; Lau, Y.C.; Pearson, J.F.; Frizelle, F.A. Molecular subtyping improves prognostication of Stage 2 colorectal cancer. BMC Cancer 2019, 19, 1-9. [CrossRef] [PubMed]

89. Chalabi, M.; Fanchi, L.; Berg, J.V.D.; Beets, G.; Lopez-Yurda, M.; Aalbers, A.; Grootscholten, C.; Snaebjornsson, P.; Maas, M.; Mertz, M.; et al. Neoadjuvant ipilimumab plus nivolumab in early stage colon cancer. Ann. Oncol. 2018, 29, viii731. [CrossRef] 